in vivo $35: 105-109(2021)$

doi:10.21873/invivo.12237

\title{
A Novel Procedure for Orthotopic Tibia Implantation for Establishment of a More Clinical Osteosarcoma PDOX Mouse Model
}

\author{
NATHANIEL F. WU ${ }^{1,2}$, JUN YAMAMOTO ${ }^{1,3}$, MICHAEL BOUVET ${ }^{3}$ and ROBERT M. HOFFMAN ${ }^{1,3}$ \\ ${ }^{1}$ AntiCancer Inc, San Diego, CA, U.S.A.; \\ ${ }^{2}$ Department of Molecular and Cellular Biology, Harvard University, Cambridge, MA, U.S.A.; \\ ${ }^{3}$ Department of Surgery, University of California, San Diego, CA, U.S.A.
}

\begin{abstract}
Background/Aim: Osteosarcoma is a rare type of malignancy that affects mostly children and adolescents. A new procedure was designed to create an improved patientderived orthotopic xenograft (PDOX) mouse model of osteosarcoma that more closely mimics osteosarcoma in clinical settings. Previous osteosarcoma PDOX models involved implanting a tumor fragment near the femur of nude mice in a space created by separating muscle. Materials and Methods: A hole was created in the tibia of nude mice and an osteosarcoma tumor fragment was implanted directly into the bone. Results: This procedure resulted in tumor growth in the bone similar to osteosarcoma tumors found in clinical patients. Conclusion: The establishment ratio for this procedure is $80 \%$ making it a practical and clinicallyrelevant model for screening effective therapies for osteosarcoma patients.
\end{abstract}

Osteosarcoma is a rare type of malignancy that affects mostly children and adolescents. Treatment with a combination of neoadjuvant and adjuvant chemotherapies with surgery improved the prognosis of patients with osteosarcoma $(1,2)$. However, patients with osteosarcoma often develop chemoresistance, especially patients with metastases, leading to fatality (1-3). Many animal studies using osteosarcoma patient-derived tumors were previously performed to attempt to identify more effective treatments (4-6). However, almost all those studies used a subcutaneous-implantation xenograft

This article is freely accessible online.

Correspondence to: Robert M. Hoffman, Ph.D., AntiCancer Inc, 7917 Ostrow St, San Diego, CA, 92111, U.S.A. Tel: +1 8586542555, Fax: +1 8582684175, e-mail: all@anticancer.com

Key Words: PDOX, patient-derived orthotopic xenograft, osteosarcoma, tibia implantation. model. Subcutaneous-implantation models are poor surrogate models of cancer in clinical patients and may not reflect effectiveness in treatment studies as accurately as orthotopicimplantation models (7). Tumor implantation at the orthotopic site can lead to metastasis, allowing the tumor to mimic the behavior of tumors observed in patients (8). We previously established an osteosarcoma patient-derived orthotopic xenograft (PDOX) mouse model where the tumor is implanted on the femur. The osteosarcoma PDOX model has identified novel treatment strategies (9-15). The present study demonstrates a new implantation procedure for osteosarcoma to the tibia bone to establish a more clinically-relevant PDOX model of this disease.

\section{Materials and Methods}

Mice. This study was conducted on athymic nu/nu nude mice (AntiCancer, Inc., San Diego, CA, USA). The procedures followed an AntiCancer, Inc. Institutional Animal Care and Use Committee (IACUC) protocol specifically approved for this study and in accordance with the principles and procedures outlined in the National Institute of Health Guide for the Care and Use of Animals under Assurance Number A3873-1. All animal procedures have been previously described (9-16).

Patient-derived tumor. The osteosarcoma tumor was previously obtained from a 14-year-old boy with pelvic osteosarcoma as part of a UCLA Institutional Review Board approved protocol (IRB\#10001857). Written informed consent was obtained from the patient (16). The patient was not administered chemotherapy or radiotherapy before the fresh biopsy sample was taken (16).

New surgical orthotopic tibia-implantation procedure to establish a more clinically-relevant osteosarcoma PDOX model. Mice containing subcutaneously-implanted tumors larger than $10 \mathrm{~mm}$ in diameter were anesthetized with a ketamine mixture and the tumors were harvested and divided into fragments of $1 \mathrm{~mm}^{3}$. An $8 \mathrm{~mm}$ incision was made in either the left or right thigh of nude mice (Figure 1A). The mouse leg was bent at the knee to expose the quadriceps and calf through the incision. The medial tibia was then 
A

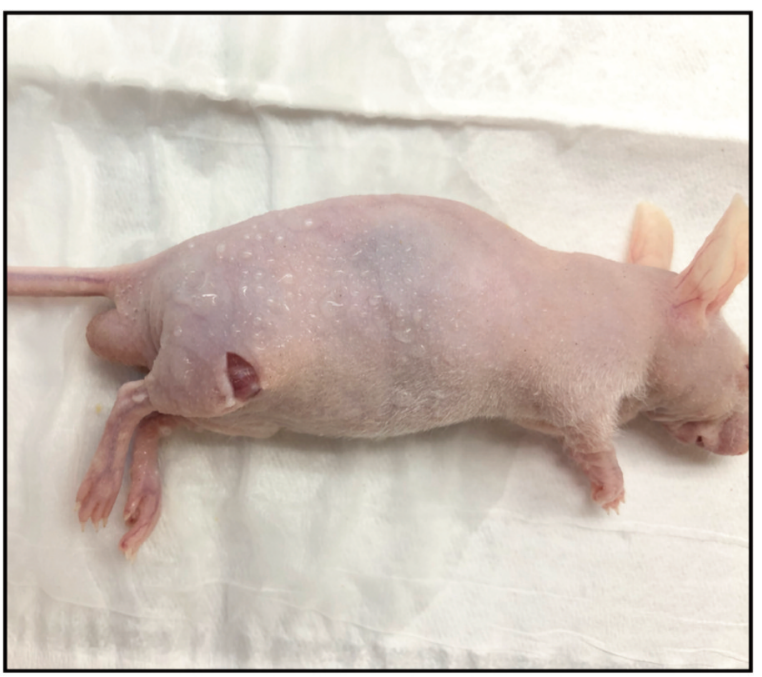

B

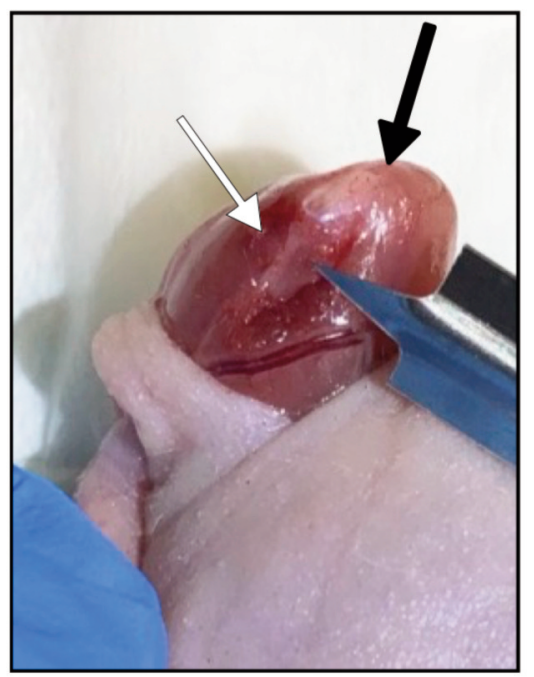

\section{C}

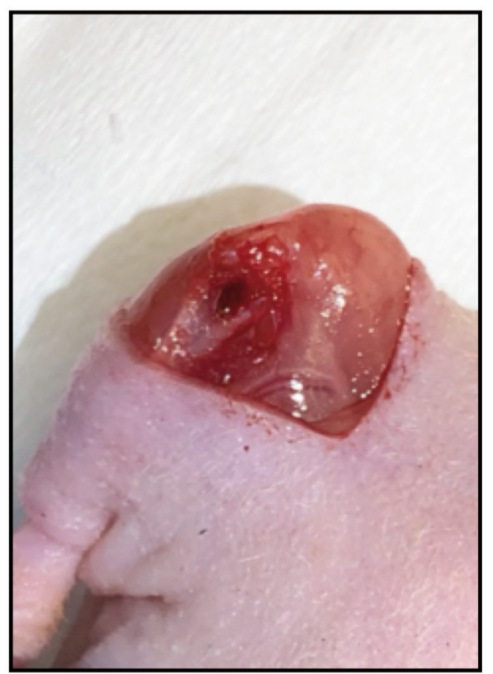

D

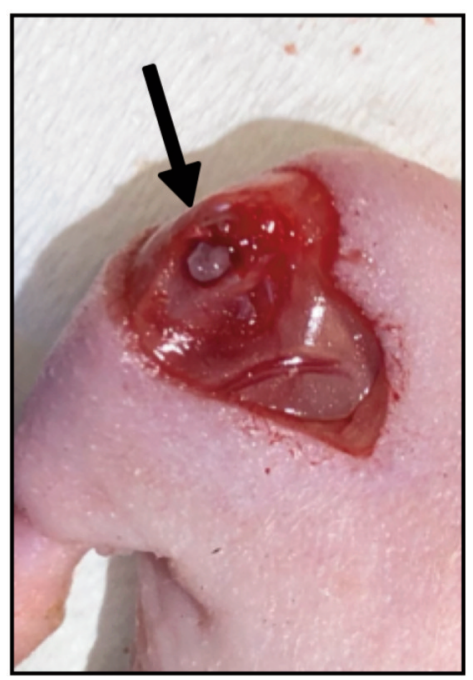

Figure 1. Bone-implantation method for osteosarcoma PDOX. (A) An 8 mm incision made on the skin. (B) Quadriceps and calf exposed by bending the knee. The membrane was dissected away from the tibia bone and muscle. Black arrow indicates the knee cap. White arrow indicates the tibia. (C) After a 5-mm blade was used to puncture a hole and was rotated, a 1 mm diameter hole was formed in the tibia. (D) A 1 -mm ${ }^{3}$ tumor fragment was inserted into the hole. Black arrow indicates the implanted tumor fragment.

visualized. The membrane was dissected to remove any membrane attachments from the lower-extremity muscle (Figure 1B). Then a $5 \mathrm{~mm}$ blade was used to puncture the proximal tibia. Once the tibia was punctured and the blade was $2.5 \mathrm{~mm}$ into the bone, the blade was rotated with multiple revolutions to create a hole in the bone (Figure 1C). Fine tweezers were used to smoothen and clean the hole. Once a $1 \mathrm{~mm}$ diameter hole was visible, a $1 \mathrm{~mm}^{3}$ tumor fragment was inserted into the hole. Fine tweezers were used to push the tumor fragment into the hole so the tumor was not raised above the bone, preventing it from falling out (Figure 1D). The incision was closed with a 5-0 PDS-II suture. Tumor size was measured with calipers 4,5 , and 6 weeks after tumor implantation. Tumor volume was calculated as described (3). All mice were sacrificed 6 weeks after implantation.
Hematoxylin and eosin staining. Fixation, paraffin sectioning, and staining were performed as previously described (10). Hematoxylin and eosin (H\&E) staining was performed according to standard protocols (15).

\section{Results}

Ten mice were implanted using the new procedure. The tumors grew in 8 mice $(80 \%)$. All tumors were detectable through the skin (Figure 2A and B). No mice had any gait disorder. The tumor volume significantly increased 4, 5, and 6 weeks after tumor implantation (Figure 3). H\&E staining showed that tumors comprised viable, highly- 
A

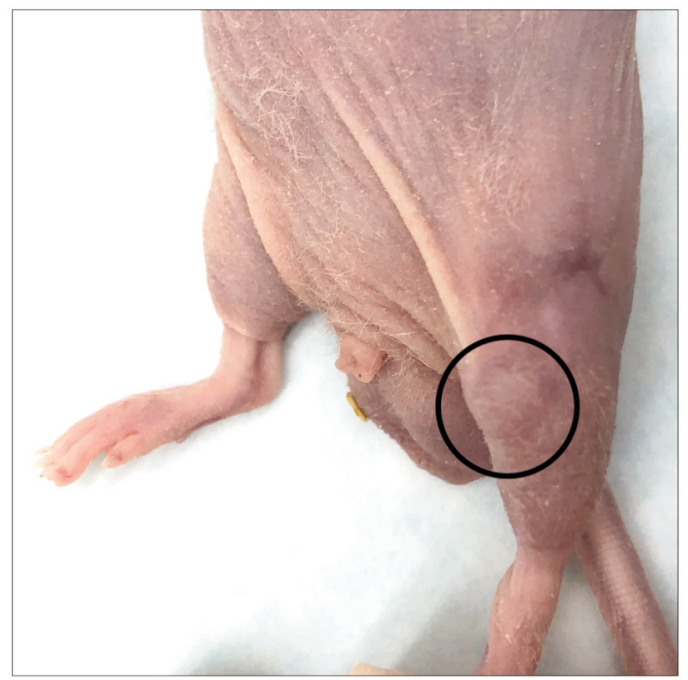

B

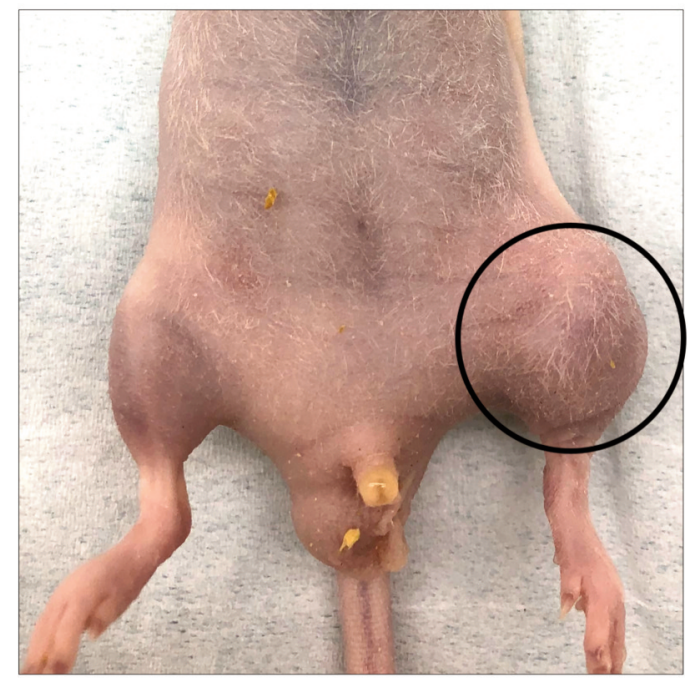

Figure 2. Osteosarcoma PDOX growth in the bone. (A) Twenty-eight days after implantation. (B) Forty-two days after implantation.

dense cancer cells with a pleomorphic spindle shape (Figure 4).

\section{Discussion}

In the present study, we established a new procedure of orthotopic implantation of osteosarcoma in the tibia bone. Compared to the previous surgical orthotopic implantation (SOI) osteosarcoma PDOX model, this new procedure is an improvement because it is a more clinically-accurate tumor model, closely mimicking what is observed in osteosarcoma patients.

The primary difference between the new procedure and the previous one is the location of tumor implantation. Instead of placing the tumor in the space between the muscle and bone, the new procedure implants the tumor directly into the bone, more accurately simulating the growth of osteosarcoma tumors in patients. Because the recess in the tibia was smaller than the space in the muscle, the tumor fragments used in these new procedures were $1 \mathrm{~mm}^{3}$ compared to $3-4 \mathrm{~mm}^{3}$ fragments used previously. However, the tumor cells were very aggressive and grew significantly and quickly in the bone despite the relatively small initial tumor size. The establishment ratio of $80 \%$ makes this new procedure practical. Moreover, this procedure is versatile. The method of creating a recess in the bone in which a tumor can be implanted can be applied to implantation into any bone. Many more bone-cancer-implantation PDOX models can be designed from this method.

This PDOX mouse model is useful for two reasons. First, individualized clinically-relevant mouse models can be made for patients with osteosarcoma. With a patient tumor,

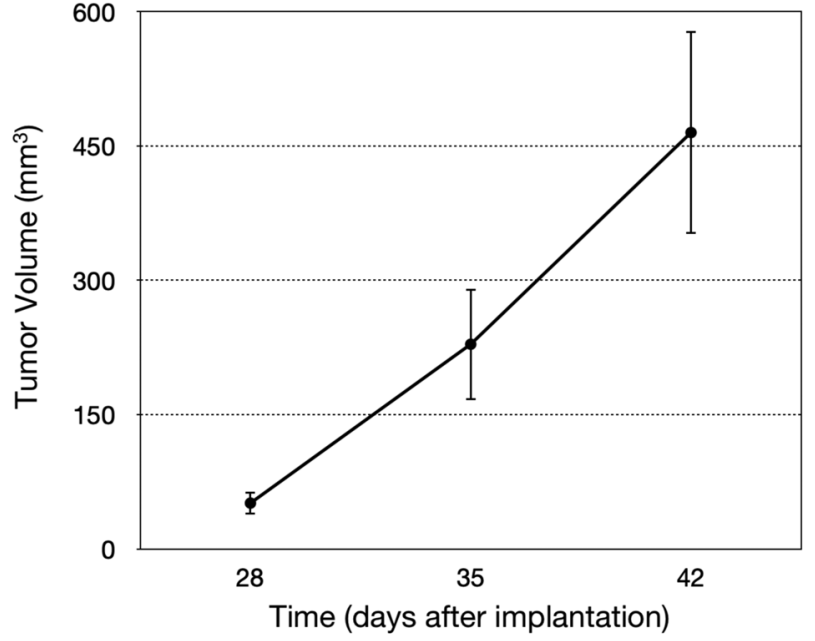

Figure 3. Quantitative osteosarcoma PDOX growth in the bone.

personal mouse models can assist in determining the most effective treatment plan for a certain patient. Second, previous osteosarcoma PDOX models have already identified potentially more effective treatments (9-16). This improved osteosarcoma PDOX model, which closely resembles clinical osteosarcoma, can be used to test novel therapies. The new procedure for tibia osteosarcoma-tumor implantation described in the present report is important, because with these improved clinically-representative mouse models, treatment experiments can be carried out with better translation to patient therapy and better understanding of the biology of the disease, in contrast to subcutaneous sarcoma mouse models (17). 
A

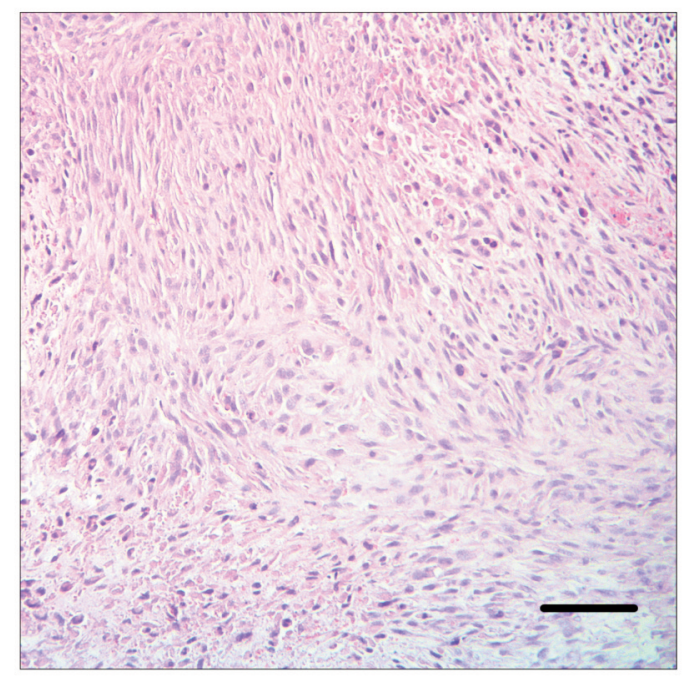

B

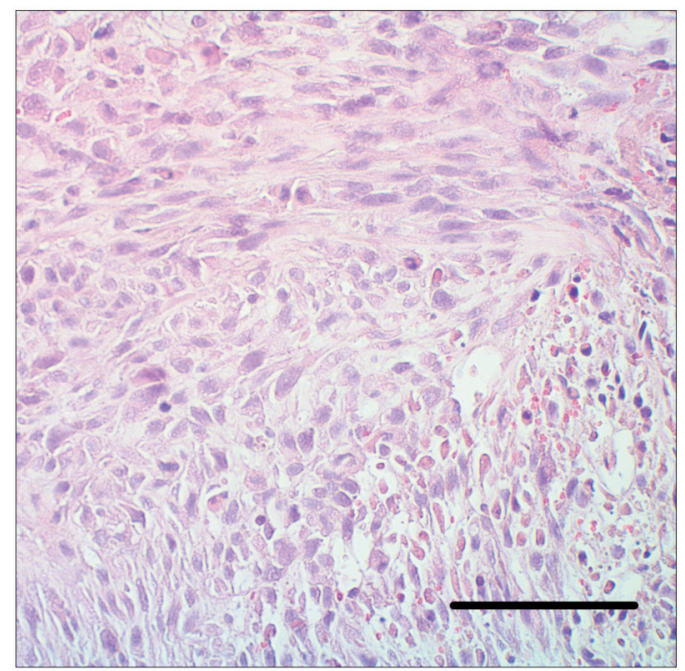

Figure 4. Tumor histology of osteosarcoma PDOX in the bone. Scale bars: $100 \mu \mathrm{m}$. (A) 100x magnification. (B) 200× magnification.

\section{Conflicts of Interest}

N.F.W., J.Y., and RMH are or were unsalaried associates of AntiCancer Inc. which performs contract research with PDOX models. The Authors declare that there are no potential conflicts of interest regarding this study.

\section{Authors' Contributions}

N.F.W. and J.Y. designed and performed experiments and wrote the paper; R.M.H. gave technical support and conceptual advice. Writing, review, and/or revision of the manuscript: N.F.W., M.B., and R.M.H.

\section{Acknowledgements}

This paper is dedicated to the memory of A. R. Moossa, M.D., Sun Lee, M.D., Professor Li Jiaxi and Masaki Kitajima, MD.

\section{Funding}

This work was supported in part by a Yokohama City University research grant "KAMOME Project", and the Robert M. Hoffman Foundation for Cancer Research, both of which had no role in the design, execution, interpretation, or writing of the study.

\section{References}

1 Durfee RA, Mohammed M and Luu HH: Review of osteosarcoma and current management. Rheumatol Ther 3(2): 221-243, 2016. PMID: 27761754. DOI: 10.1007/s40744-016-0046-y

2 Harrison DJ, Geller DS, Gill JD, Lewis VO and Gorlick R: Current and future therapeutic approaches for osteosarcoma. Expert Rev Anticancer Ther 18(1): 39-50, 2018. PMID: 29210294. DOI: 10.1080/14737140.2018.1413939
3 Igarashi K, Kawaguchi K, Murakami T, Miyake K, Kiyuna T, Miyake M, Hiroshima Y, Higuchi T, Oshiro H, Nelson SD, Dry SM, Li Y, Yamamoto N, Hayashi K, Kimura H, Miwa S, Singh SR, Tsuchiya H and Hoffman RM: Patient-derived orthotopic xenograft models of sarcoma. Cancer Lett 469: 332-339, 2020. PMID: 31639427. DOI: 10.1016/j.canlet.2019.10.028.

4 Nanni P, Landuzzi L, Manara MC, Righi A, Nicoletti G, Cristalli C, Pasello M, Parra A, Carrabotta M, Ferracin M, Palladini A, Ianzano ML, Giusti V, Ruzzi F, Magnani M, Donati DM, Picci P, Lollini PL and Scotlandi K: Bone sarcoma patient-derived xenografts are faithful and stable preclinical models for molecular and therapeutic investigations. Sci Rep 9(1): 12174, 2019. PMID: 31434953. DOI: 10.1038/s41598-019-48634-y

5 Gill J, Zhang W, Zhang Z, Roth M, Harrison DJ, Rowshan S, Erickson S, Gatto G, Kurmasheva R, Houghton P, Teicher B, Smith MA, Kolb EA and Gorlick R: Dose-response effect of eribulin in preclinical models of osteosarcoma by the pediatric pre-clinical testing consortium. Pediatr Blood Cancer 67(10): e28606, 2020. PMID: 32706456. DOI: 10.1002/pbc.28606

6 Smeester BA, Slipek NJ, Pomeroy EJ, Laoharawee K, Osum SH, Larsson AT, Williams KB, Stratton N, Yamamoto K, Peterson JJ, Rathe SK, Mills LJ, Hudson WA, Crosby MR, Wang M, Rahrmann EP, Moriarity BS and Largaespada DA: PLX3397 treatment inhibits constitutive CSF1R-induced oncogenic ERK signaling, reduces tumor growth, and metastatic burden in osteosarcoma. Bone 136: 115353, 2020. PMID: 32251854. DOI: $10.1016 /$ j.bone.2020.115353

7 Tran Chau V, Liu W, Gerbé de Thoré M, Meziani L, Mondini M, O'Connor MJ, Deutsch E and Clémenson C: Differential therapeutic effects of PARP and ATR inhibition combined with radiotherapy in the treatment of subcutaneous versus orthotopic lung tumour models. Br J Cancer 123(5): 762-771, 2020. PMID: 32546832. DOI: $10.1038 / \mathrm{s} 41416-020-0931-6$

8 Hoffman RM: Patient-derived orthotopic xenografts: Better mimic of metastasis than sub-cutaneous xenografts. Nat Rev Cancer 15(8): 451-452, 2015. PMID: 26422835. DOI: $10.1038 / \mathrm{nrc} 3972$ 
9 Higuchi T, Oshiro H, Miyake K, Sugisawa N, Han Q, Tan Y, Park J, Zhang Z, Razmjooei S, Yamamoto N, Hayashi K, Kimura H, Miwa S, Igarashi K, Bouvet M, Chawla SP, Singh SR, Tsuchiya $\mathrm{H}$ and Hoffman RM: Oral recombinant methioninase, combined with oral caffeine and injected cisplatinum, overcome cisplatinumresistance and regresses patient-derived orthotopic xenograft model of osteosarcoma. Anticancer Res 39(9): 4653-4657, 2019. PMID: 31519563. DOI: 10.21873/anticanres.13646

10 Higuchi T, Sugisawa N, Miyake K, Oshiro H, Yamamoto N, Hayashi K, Kimura H, Miwa S, Igarashi K, Bouvet M, Singh SR, Tsuchiya $\mathrm{H}$ and Hoffman RM: The combination of olaratumab with doxorubicin and cisplatinum regresses a chemotherapyresistant osteosarcoma in a patient-derived orthotopic xenograft mouse model. Transl Oncol 12(9): 1257-1263, 2019. PMID: 31299622. DOI: $10.1016 / j$.tranon.2019.06.002

11 Higuchi T, Sugisawa N, Miyake K, Oshiro H, Yamamoto N, Hayashi K, Kimura H, Miwa S, Igarashi K, Chawla SP, Bouvet M, Singh SR, Tsuchiya H and Hoffman RM: Sorafenib and palbociclib combination regresses a cisplatinum-resistant osteosarcoma in a PDOX mouse model. Anticancer Res 39(8): 4079-4084, 2019. PMID: 31366491. DOI: 10.21873/anticanres.13565

12 Higuchi T, Sugisawa N, Miyake K, Oshiro H, Yamamoto N, Hayashi K, Kimura H, Miwa S, Igarashi K, Kline Z, Belt P, Chawla SP, Bouvet M, Singh SR, Tsuchiya H and Hoffman RM: Combination treatment with sorafenib and everolimus regresses a doxorubicin-resistant osteosarcoma in a PDOX mouse model. Anticancer Res 39(9): 4781-4786, 2019. PMID: 31519579. DOI: 10.21873/anticanres.13662

13 Higuchi T, Sugisawa N, Miyake K, Oshiro H, Yamamoto N, Hayashi K, Kimura H, Miwa S, Igarashi K, Kline Z, Bouvet M, Singh SR, Tsuchiya H and Hoffman RM: Pioglitazone, an agonist of PPAR $\gamma$, reverses doxorubicin-resistance in an osteosarcoma patient-derived orthotopic xenograft model by downregulating P-glycoprotein expression. Biomed Pharmacother 118: 109356, 2019. PMID: 31545293. DOI: 10.1016/j.biopha.2019.109356
14 Higuchi T, Sugisawa N, Yamamoto J, Oshiro H, Han Q, Yamamoto N, Hayashi K, Ki-mura H, Miwa S, Igarashi K, Tan Y, Kuchipudi S, Bouvet M, Singh SR, Tsuchiya H and Hoffman RM: The combination of oral-recombinant methioninase and azacitidine arrests a chemotherapy-resistant osteosarcoma patient-derived orthotopic xenograft mouse model. Cancer Chemother Pharmacol 85(2): 285-291, 2020. PMID: 31705268. DOI: $10.1007 / \mathrm{s} 00280-019-03986-0$

15 Higuchi T, Yamamoto J, Sugisawa N, Tashiro Y, Nishino H, Yamamoto N, Hayashi K, Kimura H, Miwa S, Igarashi K, Bouvet M, Singh SR, Tsuchiya H and Hoffman RM: PPAR $\gamma$ agonist pioglitazone in combination with cisplatinum arrests a chemotherapy-resistant osteosarcoma PDOX model. Cancer Genomics Proteomics 17(1): 35-40, 2020. PMID: 31882549.

16 Higuchi T, Miyake K, Oshiro H, Sugisawa N, Yamamoto N, Hayashi K, Kimura H, Miwa S, Igarashi K, Chawla SP, Bouvet M, Singh SR, Tsuchiya H and Hoffman RM: Trabectedin and irinotecan combination regresses a cisplatinum-resistant osteosarcoma in a patient-derived orthotopic xenograft nudemouse model. Biochem Biophys Res Commun 513(2): 326-331, 2019. PMID: 30955860. DOI: 10.1016/j.bbrc.2019.03.191

17 Marchetto A, Ohmura S, Orth MF, Knott MML, Colombo MV, Arrigoni C, Bardinet V, Saucier D, Wehweck FS, Li J, Stein S, Gerke JS, Baldauf MC, Musa J, Dallmayer M, Romero-Pérez L, Hölting TLB, Amatruda JF, Cossarizza A, Henssen AG, Kirchner T, Moretti M, Cidre-Aranaz F, Sannino G and Grünewald TGP: Oncogenic hijacking of a developmental transcription factor evokes vulnerability toward oxidative stress in Ewing sarcoma. Nat Commun 11(1): 2423, 2020. PMID: 32415069. DOI: 10.1038/s41467-020-16244-2

Received November 3, 2020

Revised November 21, 2020

Accepted November 25, 2020 